\section{Pleiotropic Functions of RB Protein in Tumor Suppression}

\section{Abstract}

$R B$ tumor suppressor gene product ( $p R B$ ) has been proposed to interact with more than 200 cellular proteins. In addition to the phosphorylation, carried out by cyclindependent kinases (CDKs), pRB undergoes various types of post-translational modifications. The post-translational modifications of $\mathrm{pRB}$ affect the binding status with numerous effector molecules including the E2F family transcription factors, proteins with LXCXE motifs, and proteasome-related proteins. This variability of effector molecules enables $p R B$ to exert pleiotropic functions. These functions also differ remarkably depending on the cell lineage and cellular context. Therefore, many recent reviews have referred to $\mathrm{pRB}$ as an adaptor protein based on its functions, in addition to as a pocket protein based on its structure. E2F family members have been critically implicated in pRB functions to drive cell cyclerelated events, yet consists minority of effector molecules in terms of number. In addition, E2Fs also target numerous genes those are not directly involved in the cell cycle control. Therefore, we speculate that pRB performs numerous cell cycle-independent functions in both E2F-dependent and -independent manners. This review, although without strictly discriminating between E2F-dependent and -independent functions, aims to describe the canonical and non-canonical functions of pRB.

Keywords: RB, Tumor suppressor, E2Fs, Cell cycle, Differentiation, Metabolism

\section{Naoyuki Hayashi i,2 Chiaki Takahashi1*}

\section{Division of Oncology and Molecular Biology, Cancer Research Institute, Kanazawa University, Kakuma-machi, Kanazawa, Ishikawa 920-1192, Japan \\ 2 Department of Food and Nutrition, Kanazawa Gakuin College, 10 Sue- machi, Kanazawa, Ishikawa 920- 1392, Japan}

\section{Corresponding author: Chiaki Takahashi}

\section{$\equiv$ \\ chtakaha@staff.kanazawa-u.ac.jp}

Chiaki Takahashi, Division of Oncology and Molecular Biology, Cancer Research Institute, Kanazawa University, Kakumamachi, Kanazawa, Ishikawa 920-1192, Japan

Tel: $+81-76-264-6750$

Fax: $+81-76-234-4521$

\section{Introduction}

The loss-of-function mutation in the $R B$ tumor suppressor gene at tumor initiation occurs in surprisingly few types of cancer. The inactivation of the $R B$ product is often found during the progression of common types of cancers including prostate, breast, bladder, and esophageal cancers [1]. Most canonical function of $\mathrm{pRB}$ is to control cell proliferation that is achieved by preventing inappropriate entry of the cell into the cell cycle. This was experimentally confirmed by cell cycle re-entry upon $R B$ inactivation in several tissues [2-4].

In vivo analyses of genetically engineered mice and in vitro experiments contributed to determining many of the canonical functions of $p R B$ in cell cycle control and differentiation. During embryonic hematopoiesis, the loss of RB in mouse embryos results in inefficient enucleation and incomplete terminal differentiation of erythroid cells $[5,6]$. During skeletal muscle development, pRB is required for the cells to properly exit the cell cycle and to complete differentiation [7]. A myogenic transcription factor, MyoD, activates expression of pRB and Cdkn1a (p21) to enforce cells to exit the cell cycle [8]. pRB is also required for reorganization of the lamin speckles during the myogenic process [9]. In the intestine of mice, when $R B$ is conditionally deleted, differentiation markers showed abnormal patterns, and proliferative crypt cells exhibited enhanced proliferation $[10,11]$. In the lens, the loss of $R B$ altered the expression of genes promoting differentiation, including $\beta$ - and $\gamma$-crystallines [12]. These deficiencies in differentiation following PRB inactivation seem at least partially due to a defect in exiting the cell cycle, which is a critical step for most differentiation processes [1]. In addition, pRB controls the pluripotency of cells, independent of the cell cycle $[13,14]$. Therefore, pRB is not only a cell cycle regulator, but also a key factor that controls cellular dedifferentiation and transformation. pRB is also implicated in numerous varieties of biological events such as cell death, DNA damage response, cellular senescence, genomic instability, cellular metabolism, inflammation, and angiogenesis [15-19].

In this review, in as much as space allows, we describe the molecular bases for the pleiotropic functions of pRB and its family members p107 and p130, which involve upstream signaling, effectors, and context-dependent targeted genes. 


\section{Regulation of $\mathrm{G}_{\mathbf{1}}-\mathrm{S}$ Transition by $\mathrm{pRB}$}

pRB has domain structures named pocket $A, B$, and $C$ [20]. These domains individually or in combination contribute to the physical binding of many factors (effectors) involved in cell proliferation, transcriptional regulation, chromatin modification, signal transduction, apoptosis, etc. Therefore, canonically, pRB has been called a pocket protein. On the other hand, the reason for this gene being called an adaptor protein is that PRB undergoes various post-translational modifications by different types of signals and this process alters its binding affinity to effectors [17]

The most common post-translational modification on $\mathrm{pRB}$ that alters its functions is phosphorylation by kinase complexes consisting of CDK4 or CDK6 and cyclin D, which occurs in late $G_{1}$ phase to early $S$ phase ( $G_{1} / S$ transition), and the subsequent release of E2F transcription factors promotes progression to the $S$ phase [21]. The E2F family proteins are classified into activators including E2F1, E2F2, and E2F3, and into repressors including E2F4 and E2F5. E2F6, E2F7, and E2F8 have been additionally identified, and currently being analyzed. It is also possible that E2F4 and E2F5 activate gene transcription under certain conditions [22]. Especially, E2F4 may transactivate several genes whose products are involved in the $G_{2} / M$ phase [23-25]. During the $G_{1}$ phase, pRB forms a transcriptional repressive complex with histone deacetylase (HDAC) and the nucleosome remodeling complex hSWI/SNF. This machinery primarily represses the expression of cyclin $E$ and A genes. Phosphorylation of $p R B$ by CDK4/cyclin D allows HDAC to dissociate from the complex, relieving repression of cyclin $E$ and thereby promoting cell cycle entry into the $S$ phase. However, the phosphorylated pRB and hSWI/SNF complex persists on the promoter of genes encoding cyclin $A$ and $C D C 2$, inhibiting cell cycle exit from the $S$ phase [26]. These processes explain the sequential expression of cyclin $E$ and $A$ during the cell cycle.

There are 13 amino acid residues in the pRB protein that are possibly phosphorylated by CDK4 or CDK6 [27]. In these phosphorylation sites, the $608^{\text {th }}$ serine residue $(\mathrm{S} 608)$ that resides between pocket $A$ and $B$ determines the binding affinity to the transactivation domain of E2F1, E2F2, and E2F3. These factors transactivate genes implicated in cell cycle progression and nucleotide synthesis such as $C D C 6$, cyclin $E$, replication protein C, DNA ligase, and DNA topoisomerase [23,28-30]. Cell cycle and bone development defects in $R B$-deficient mouse embryos were suppressed by the simultaneous deletion of E2F1 [31]. In addition, numerous reports have indicated that E2Fs play a key role in mediating $\mathrm{pRB}$ function to regulate cell cycle and differentiation.

Besides the E2F-mediated transcriptional control, pRB has alternative mediators to regulate DNA replication. Hypophosphorylated pRB specifically binds to the largest subunit of the origin recognition complex (Orc1); this interaction competes with E2F1 on binding to $\mathrm{pRB}$ (Figure 1). During the transition from the $G_{1}$ phase to the $S$ phase, E2F1 out-competes Orc1 from pRB at replication origins [32]. The functional relationship with Orc1 represents one of the E2F-independent functions of $\mathrm{pRB}$.

$R B^{+/-}$mice developed pituitary and thyroid tumors as a consequence of biallelic loss of $R B$ in somites. Simultaneous deletion of E2F1 significantly suppressed thyroid tumorigenesis [33]. In contrast, deletion of E2F3 accelerated malignant progression of $R B$-deficient thyroid tumor [34]. Interestingly, $R B^{D 326 V /+}$ mice develop pituitary but not thyroid tumors. This observation is in line with the result of an in vitro binding assay indicating that mutated $\mathrm{pRB}^{\mathrm{D} 326 \mathrm{~V}}$ could bind to E2F1 but not to E2F2/3 [35]. Thus, the relationships between pRB and each of E2F family members are functionally distinct.

On the other hand, the introduction of the RB D750F/D750F mutation, which is able to inhibit E2F transactivation activity but unable to interact with LxCXE-motif proteins, including HDACs, heterochromatin protein 1 (HP1),, histone methyltransferase Suv39h1, and CtBP-interacting protein, caused cell cycle arrest upon mitogen deprivation or cell-cell contact, but did not cause cell cycle arrest upon $\operatorname{Ras}^{\mathrm{V} 12}$ introduction or irradiation [36]. This result supports the argument that pRB-binding partners determine cell behaviors that differ depending on cellular context.

\section{Regulation of Mitosis by pRB}

In addition to phosphorylation, dephosphorylation of pRB is crucial for cell cycle control, especially during mitosis (Figure 1) [37]. Upon exiting mitosis, pRB is dephosphorylated by protein phosphatase 1 (PP1) [38]. In fact, direct binding between PP1 catalytic subunit (PP1c) and $\mathrm{pRB}$ has been observed during mitosis [39]. Before initiating PRB phosphorylation, CDK/cyclin complexes out-competes PP1 [40]. Moreover, PP1 nuclear targeting subunit (PNUTS) specifically inhibits the activity of PP1 to dephosphorylate pRB $[41,42]$.

pRB is involved in checkpoints and maintenance of mitosis as well as in the transition from the $G_{1}$ phase to the $S$ phase. Chromosomal instability accompanied by abnormal spindle formation and impaired cohesion were also observed in pRB-deficient cells $[43,44]$. The expression of Mad2, a component of the mitotic checkpoint, is induced by E2Fs released from pRB [45]. Mad2 ensures proper progression to anaphase, as it blocks anaphasepromoting complex/cyclosome (APC/C). An aberrant expression of Mad2 caused by $\mathrm{PRB}$ defects may generate a hyperactive response to spindle checkpoint, causing an abnormal order of mitotic events and low accuracy of chromosomal segregation. Persistent inactivation of the APC/C by excess amounts of Mad2 may delay the degradation of securin and cyclin $\mathrm{B}$. Cdc20 protein, which is an activator of APC/C, functions as a co-transactivator of the $U B C H 10$ gene, which encodes the E2 ubiquitin carrier protein [46]. Cdc20 interacts with the E2F1-DP1 complex at the promoter region of $U B C H 10$ to stimulate its transcription, and pRB represses this transactivation [47]. pRB inactivation leads to deregulation of $U B C H 10$ expression, which may cause lower accuracy of chromosomal segregation (Figure 2). Moreover, pRB directly binds to the nuclear mitotic protein, NuMa, which organizes the mitotic spindle [48]. Since this binding occurs during the transition from interphase to prophase, it may control timing of the spindle formation or prevent mitotic segregation caused by premature chromosomal arrangement.

Moreover, pRB controls genomic stability. Malignant tumor progression is caused by pRB-deficiency, which induces aneuploidy and genomic instability [49]. It is also observed in 


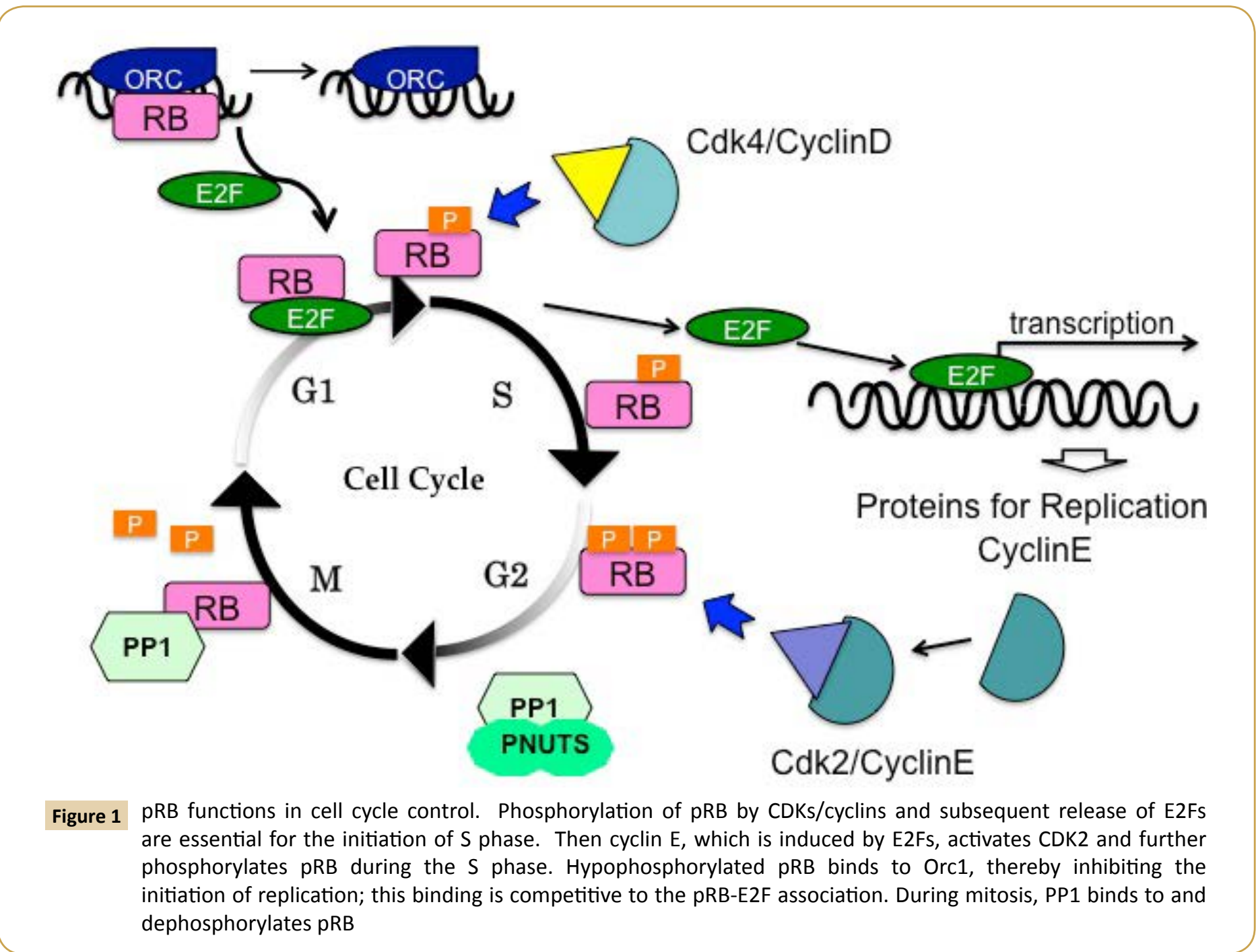

cultured cell lines upon pRB inactivation [45,50-52]. Furthermore, hepatitis $C$ virus (HCV) infection, which often causes polyploidy, decreased the effects of mitotic checkpoints due to the reduction of $R B$ transcription and the induction of E2F1 and Mad2 [53]. Loss of $p 53$ seems to render the cells resistant to cell cycle arrest, following chromosomal mis-segregation induced by $\mathrm{pRB}$ deficiency. Therefore, simultaneous inactivation of $\mathrm{pRB}$ and p53 results in high levels of chromosomal instability [54]. The functional synergy between pRB and p53 will be discussed again later.

\section{Post-translational Modification of pRB}

The pRB-E2F1 complex plays a pivotal role in regulating apoptosis, in a manner distinct from that for transcriptional control during the cell cycle [55-58], and for enhancing resistance to phosphorylation by $\operatorname{CDK}[59,60]$. Specific phosphorylation of human E2F1 at S364 that occurs in response to DNA damageinduced double strand breakages enhances the formation of the pRB-E2F1 complex, even when pRB is hyperphosphorylated; this process subsequently transactivates a number of proapoptotic genes [55].

Acetylation of pRB by p300 is required for cell cycle exit during skeletal myogenesis in mice [61]. In addition, acetylation of pRB at $\mathrm{K} 873$ and $\mathrm{K} 874$ in the $\mathrm{C}$-terminus region of pRB, where E2F1 binds to, occurs in response to DNA damage, which releases E2F1 from $p R B$ [62].

Furthermore, methylation at $\mathrm{K} 810$ in $\mathrm{pRB}$ by the Set7/9 methyltransferase, which prevents subsequent phosphorylation of pRB, is required for efficient cell cycle arrest [63]. This methylation inhibits the phosphorylation of serine residues $\mathrm{S} 807$ and S811 in the vicinity. Phosphorylation at these serine residues by 5 '-AMPactivated protein kinase (AMPK) is required for proliferation of neural stem and progenitor cells (NPC) in the mouse brain [64]. In some lineage of cells including NPC, metabolic stimuli to control cell proliferation are mediated through the AMPK-pRB pathway rather than through the CDK-pRB pathway. On the other hand, a putative oncoprotein, SET and MYND domain-containing protein 2 (SMYD2), whose overexpression is often observed in esophageal squamous cell carcinoma cells, also methylates K810 in pRB, and the methylation by SMYD2 facilitates phosphorylation at $\mathrm{S} 807$ and S811 by CDK4 [65]. The growth suppression of cancer cells by SMYD2 knock-down is possibly due to the altered methylation in $\mathrm{PRB}$.

In endothelial cells exposed to oxidative stress, rapid 


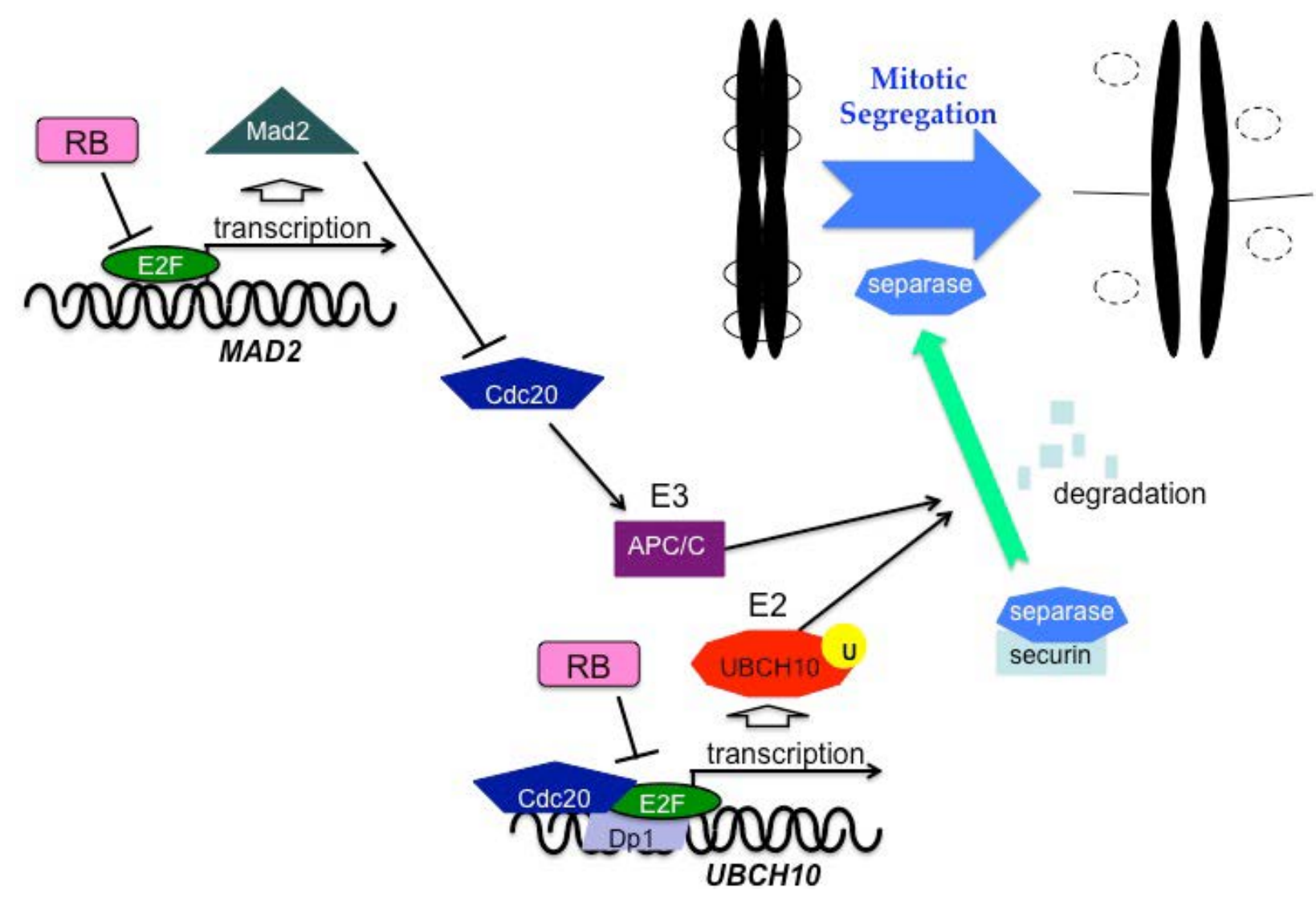

Figure 2 pRB functions in controlling mitotic checkpoints. The transactivation of MAD2 and UBCH1O genes by E2F is repressed by $\mathrm{pRB}$ binding. Mad2 protein, in response to spindle disassociation, inhibits Cdc20, inactivating $\mathrm{APC} / \mathrm{C}$. UBCH10 protein is an E2 enzyme that degrades securin, which prevents the initiation of chromosomal segregation by separase. Loss of pRB may cause over-production of these regulatory proteins that play critical roles in mitosis.

dephosphorylation of the pRB family of proteins was observed, which appeared to depend on protein phosphatase 2A (PP2A); this enhances pRB-E2Fs association [66]. UV stress caused the rapid dephosphorylation of p107 by PP2A holoenzymes $[67,68]$. However, growth arrest by FGF or all-trans retinoic acid was mediated by dephosphorylation of p107 or p130 in a PP2Adependent manner [69-71]. Dephosphorylation at two residues, S1080 and T1097, adjacent to the nuclear localization signal (NLS) in p130 induced its translocation to the nucleus due to increased binding affinity of importins to this NLS [72]. Moreover, hypoxia (1\% oxygen) and oxidative stress caused dephosphorylation of the pRB family proteins by PP1 and PP2A, which reduces the efficiency of DNA replication [66]. Thus, the phosphorylation status of pRB and its family members are dynamically controlled by the equilibrium between CDKs and PP1 or PP2A throughout the cell cycle. A recent study using chemotherapeutic reagents suggested that PP1 but not PP2A is directly involved in dephosphorylation of pRB. PP2A might affect the phosphorylation status of PP1c and/or its regulatory proteins [73]. These findings suggest that the effects of post-translational modifications in pRB and other pocket proteins differ depending on cellular context.

\section{Epigenetic Regulation by pRB}

As aforementioned, pRB controls its targeted gene transcription mainly via E2Fs. Genes targeted by E2Fs include those promote $S$ phase, chromatin assembly, condensation, segregation, and spindle formation [25], but a considerable percentage of those genes might be regulated through $\mathrm{pRB}$ function to modulate the epigenetic status of the genome [74]. The pRB-E2F complex suppresses gene transcription at least partly by recruiting HDAC1 and 2 [75]. Histone H4 acetylation status on E2F targeted promoters varies in a cell cycle-dependent manner [75-77]. pRB interacts with the histone methyltransferases and HP1 $[78,79]$. Loss of pRB resulted in disappearance of trimethylated K20 histone $\mathrm{H} 4$ from the heterochromatin domain [80]. As described above, pRB interacts with HDAC and the hSWI/SNF complex to repress expression of cyclin $E$ and $A$ during the $G_{1}$ phase.

In addition, pRB controls the methylation status of the genome, by binding to DNA methyltranferase 1 (DNMT1). Through this interaction, $\mathrm{pRB}$ reduces DNA methylation levels in the genome [81], while DNMT1 cooperates with pRB-E2Fs to suppress transcription via HDAC1 [82].

There are several alternative pathways where pRB controls 
DNMT1 activity. Attenuation of pRB expression stimulates ATM expression depending on E2F, whereas pRB appeared to cooperate with ATM to regulate the stability of DNMT1 by controlling its complex formation with a specific E3 ligase UHRF1 [83]. On the other hand, through direct binding at the AP-1 site, pRB and c-JUN upregulate the DNMT1 promoter in early passage mesenchymal stromal cells (MSCs) $[84,85]$. In non-MSCs, pRB was found to bind to the E2F1 binding site but not to the AP-1 site in the DNMT1 promoter [84], implicating that the functional interactions between pRB and DNMT1 might be critical for epigenetic regulation that determines lineage commitment and the differentiation status of cells.

\section{pRB Functions To Control Cellular Me- tabolism}

pRB is deeply implicated in the regulation of cellular metabolism [18]. This would be highly helpful to adjust the metabolic status to demands to increase biomass upon cell proliferation. Cancer cells are most remarkably characterized by altered cellular metabolism. Most cancer cells achieve aerobic glycolysis that is inefficient to generate ATP, while normally differentiated cells rely much on oxidative phosphorylation to generate energy. This phenomenon is called the Warburg's effect.

The role of $\mathrm{pRB}$ in cancer metabolism is being extensively studied recently $[18,86]$. The $\mathrm{pRB}-\mathrm{E} 2 \mathrm{~F}$ pathway regulates cellular proliferation in response to glucose stimulation. E2F1 induces the expression of Kir6.2, which constitutes the ATP sensitive potassium channel, thereby regulates insulin release from pancreatic-cells. Meanwhile, CDK4 is activated by the insulin signal in response to glucose stimulation, resulting in activation of E2F1 [87].

pRB is implicated in controlling many of the genes involved in fatty acid and cholesterol biosynthesis. The promoters of these genes possess sterol regulatory elements (SRE), E2F-binding consensus sequences, or both. $R B$ inactivation causes an E2Fdependent induction of farnesyl diphosphate synthase, several prenyltransferases, and transcriptional activator sterol regulatory element-binding proteins (SREBPs), thus the isoprenylation status of proteins including $\mathrm{N}$-Ras is affected by the presence of pRB [88].

While human cancers without functional pRB exhibits an increased glutamine-uptake, triple knock-out of the $R B$ family of genes in mouse embryonic fibroblasts (MEFs) also increased glutamine consumption, due to upregulation of the glutamine transporter ASCT2 [89]. Loss of RB family members resulted in higher glutamine utilization in the TCA cycle and glutathione accumulation. Moreover, these cells became more dependent on glutaminolysis [89]. Thus, pRB family members may play a key role in rewiring glutamine metabolism and glutathione synthesis in tumor cells.

pRB and E2F1 can also regulate oxidative metabolism by modulating the expression of several genes involved in mitochondrial biogenesis $[90,91]$. During differentiation of white and brown adipocytes that takes place depending on the status of $\mathrm{pRB}$, mitochondrial gene expression pattern and number are altered. The pRB-E2F1 complex binds to the promoters of many of the genes implicated in oxidative metabolism in brown adipose tissue and muscle. When exposed to cold or fasting conditions, pRB undergoes higher rates of phosphorylation, stimulating oxidative metabolism [90,92]. Thus, pRB detects changes in the extracellular space and directs cell metabolism in response.

\section{pRB in tumor progression}

Mice carrying a point mutation in $R B$ that impedes the ability to interact with the transactivation domain of E2Fs showed relatively normal development and did not develop cancer throughout their lives [60]. Interestingly, MEFs with a pRB mutation that specifically disrupts interactions with E2Fs, were able to arrest the cell cycle upon serum starvation at an efficiency similar to that of wild type MEFs, but their capability of progressing the cell cycle upon serum stimulation was impaired to a level similar to that of $R B$ knock-out cells [60]. In short, cell cycle arrest can be achieved by $p R B$ without the help of E2Fs. These results suggest that the pRB function in transcriptional control via the interaction with E2Fs is distinguished from the $\mathrm{pRB}$ function in tumor suppression. Therefore, pRB deficiency gives rise to a variety of consequences due to its pleiotropic functions that differ depending on cellular types and stages of tumor development. For example, heterozygosity of retinoblastoma gene $R B^{+/-}$tends to arise thyroid C cell tumors, but the $R B^{+/-} S k p 2^{-/}$mice did not appear the tumor in thyroid glands. Elimination of p27 phosphorylation, which avoid ubiquitination by $\mathrm{SCF}^{\text {skp2 }}$, showed the same effect given by the Skp2-null background [93]. This suggests that downregulation of p27 by ubiquitination under the SCF $^{\text {SKP2 }}$ system supported aberrant proliferation in $R B$-deficient cells.

$R B$ mutations in early stage tumorigenesis are detected in certain types of malignancies such as retinoblastoma, osteosarcoma, and small cell lung cancers. In the majority of cancers, pRB inactivation is more prevalent during the later stage of tumor development. pRB is uniquely indispensable to prevent precursor proliferation of cones in the retina, implicating absolute requirement of $R B$ dysfunction for the initiation of retinoblastoma [94]. On the other hand, pRB is typically intact at early stages of prostate carcinogenesis. The inactivation of $\mathrm{pRB}$ at later stages allows E2F1 to activate the expression of androgen receptor, which is essential for tumor progression and metastasis [95]. Furthermore, the pRB downregulation reduces the expression level of E-cadherin; this gives rise to a mesenchymal-like phenotype in breast cancer cells thereby promotes invasion and metastasis [96].

\section{Functional Synergy between pRB and p53}

pRB and p53 are the targets for the proteins produced by oncogenic DNA viruses. For example, the E7 protein of human papillomaviruses (HPVs) binds to pocket proteins, pRB, p107, and $\mathrm{p} 130$, synergistically inhibiting their functions [97]. HPV E7 also binds to and activates E2F1; this blocks E2F6 function to counteract E2F1 function [98]. On the other hand, the E6 protein of HPVs stimulates ubiquitination of p53 [99]. These findings indicate that the dual inhibition of $\mathrm{pRB}$ and $\mathrm{p} 53$ by HPV proteins promotes cancer initiation.

Apoptosis and cellular senescence are crucial processes to 
avoid malignant progression, and are mostly controlled by $\mathrm{p} 53$, pRB in cooperation with other tumor suppressors. p53 and pRB cooperate in multiple steps in these mechanisms, suggesting why double mutation of these genes is often detected in cancers. Loss of pRB function can lead to apoptosis mediated by E2F1 and then by ARF, an upstream regulator of $p 53[100,101]$. Thus, pRB functions in a considerably different way in the absence of $p 53$. Knockdown of either one of p53, p21, or pRB restored proliferative properties in cells, which were arrested by loss of the three ras loci, $\mathrm{H}-, \mathrm{N}$ - and $\mathrm{K}$-ras, implicating pRB-p53-p21 function in the identical process $[102,103]$. However, a recent study demonstrated that a double inactivation of pRB and p53 resulted in an undifferentiated status in MEFs without inducing carcinogenesis [104]. This phenomenon was not fully achieved in cells deficient of either one of pRB or p53, indicating that their functions acted in distinct pathways.

A considerable portion of pRB proteins localize to the mitochondria and play pivotal roles in regulating mitochondrial apoptosis in a transcription-independent manner $[105,106]$. Surprisingly, this regulation is attained via the direct interaction of pRB with one of the Bcl2 protein family members, Bax [106]. Bax increases permeability of the mitochondrial outer membrane (MOMP), releasing proapoptotic factors such as cytochrome c and leading to activation of effector caspases [107]. The status of mitochondrial pRB was affected by a wide variety of proapoptotic signals, which is one of the non-canonical functions of $p R B$ in tumor suppression [106]. Phosphorylation of pRB at $\mathrm{S} 807$ appeared to be critical for the interaction with Bax [108]. Hence, dephosphorylation of $\mathrm{pRB}$ results in its dissociation from Bax. However, knockdown of PNUTS, which would activate PP1 that dephosporylates $\mathrm{S} 807$ in pRB, induced apoptosis [109-111]. It is thus unclear whether release of Bax from pRB is required for mitochondrial apoptosis. On the other hand, dephosphorylation of pRB at T821 that occurs in response to cellular stress, such as UV or CDK inhibitors, stimulated apoptosis [112,113]. Whether the phosphorylation status of pRB at T821 affects the binding between $\mathrm{pRB}$ and Bax is not yet clarified.

In mitochondrion, p53 also directly interacts with anti-apoptotic proteins such as $\mathrm{Bcl} 2$ or $\mathrm{Bcl}-\mathrm{X}_{\mathrm{L}}$. This interaction results in activation of proapoptotic Bax and Bak proteins [114]. The overlapped pRB and p53 functions in controlling apoptosis would explain the necessity for inactivation of pathways related to both tumor suppressors for tumorigenicity $[115,116]$. Interestingly, the non-cell autonomous function that suppresses apoptosis in $R B$ deficient cells occurred after p53 induction in neurons of chimeric mice [117]. It may caused by some survival signals or Bax inhibition from neighbor cells. Moreover, a study using tetraploidy technique showed an extraembyonic function of the $R B$ gene. $R B^{-/}$embryos, when supplied with wild-type placenta, did not show abnormal development in the central nervous system (CNS), and survived until birth, however died after birth due to severe skeletal muscle defects $[118,119]$. In lens development, $R B$, however, appeared to function in a perfectly cell autonomous manner [119]. Therefore, during embryonic development, pRb could function in both non-cell and cell autonomous manners. Molecular aspects of the non-cell autonomous phenomena in RB-/cells during development are remained to be elucidated.

\section{Pocket Proteins under the Control of Transforming Growth Factor $\beta$}

Transforming growth factor (TGF) $\beta$ exerts tumor-suppressing activities at least partially via the regulation of MCM7. The helicase activity of this molecule is directly inhibited by $\mathrm{pRB}$ [120-122]. The MCM complex is recruited to origin recognition complexes to initiate transcription through its helicase activity in early $S$ phase. The MCM7-pRB interaction mediated by TGF $\beta$ prevents pre-replication complex activation by the MCM complex until the $G_{1} / S$ boundary is reached [122]. TGF $\beta$ stimulates E2F4/5 to form complexes with HDAC and pocket proteins $\mathrm{p} 107$ or $\mathrm{p} 130$, resulting in the expression of C-MYC or CDC25A, respectively $[123,124]$. Overexpression of MCM7 is observed in a wide range of cancers. Furthermore, suppression of MCM7 decreased BrdU incorporation in lung and bladder cancer cells [125]. Additionally, TGF $\beta$ stimulates E2F1 to form a complex with p300/CREBbinding protein-associated factor (P/CAF), allowing $p R B$ to induce proapoptotic proteins [126]. The E2F1-pRB-P/CAF complex also induces proapoptotic proteins such as p73 and caspase7 in response to DNA damage [57]. Thus, pRB in cooperation with its family members plays a pivotal role in deciding whether to allow cells to go through apoptosis or to progress through the cell cycle.

\section{pRB in Cellular Senescence}

The formation of senescence-associated heterochromatin foci (SAHF) contributes to cell cycle exit by directly silencing proliferation-promoting genes [127-130]. During the SAHF formation, PRB cooperates with histone chaperones HIRA/ ASF1a [131]. Phosphorylation of HIRA and HP1 promotes SAHF formation by recruiting macroH2A, HP1Y, or HMGA $[130,131]$. pRB and p16INK4a are indispensable for SAHF formation induced by oncogene Ras, but $\mathrm{p} 53$ and $\mathrm{p} 21^{\mathrm{CIP1}}$ are dispensable $[128,132]$. In addition, the induction of SAHF in response to DNA-damage required the mitogen-activated protein kinase p38 [133]. It is also notable that $\mathrm{PRB}$ is required for the senescence-associated loss of trimethylated $\mathrm{K} 4$ histone $\mathrm{H} 3$, which is dependent on $\mathrm{H} 3 \mathrm{~K} 4$ demethylases including Jarid1a and Jarid1b [134].

Activation of oncogene products such as Ras triggers cellular senescence, a state of irreversible cell growth arrest when cells are mostly intact; this is called oncogene-induced senescence (OIS) $[127,135]$. In OIS, pRB and E2Fs colocalize to Promylocytic leukemia (PML) bodies and suppress E2F targeted promoters [136,137]. Of the E2F family members, only E2F7 is upregulated in OIS. Once induced, E2F7 represses expression of the E2F-targeted genes. Of the E2F family members, only E2F7 is capable of compensating for the loss of $\mathrm{pRB}$ to suppress mitotic genes [138].

Knockdown of pRB in cells reversed the changes in gene expression during senescence and allowed them to reenter the cell cycle, while knockdown of p107 or p130 could not reverse the changes of senescence [139]. This effect represents an unique function of pRB in inducing cellular senescence. Yet, senescence induced by pRB inactivation depends on the function of p130 [88], suggesting redundant functions shared by $\mathrm{pRB}$ family members in controlling cellular senescence. 


\section{Conclusion}

In this review article, we collected the published findings of the pleiotropic aspects of $\mathrm{pRB}$ function, and tried to connect them to the interaction with numerous binding partners. Because of the space limitation, we did not refer to the recent progress in our understanding of $\mathrm{pRB}$ functions in stem cells, inflammation, and other unexpected aspects of metabolic control. We propose that, in light of its strong clinical relevance, pRB should be continuously studied to elucidate its functions relating to different steps during carcinogenesis, which would be a valuable resource for cancer therapeutics.

\section{Acknowledgment and Grant Support}

We thank Dr. Shunsuke Kitajima for critical reading of this manuscript. This work was supported by Funding Program for Next Generation World-Leading Researchers (NEXT), Grantin-Aid for Scientific Research (MEXT), Astellas Foundation for Research on Metabolic Disorders, Takeda Science Foundation, Naito Foundation, Daiichi-Sankyo Foundation for Life Science, NOVARTIS Foundation (Japan) for Promotion of Science and Hokkoku Foundation for Cancer Research to CT. 


\section{References}

1 Burkhart DL, Sage J (2008) Cellular mechanisms of tumour suppression by the retinoblastoma gene. Nat Rev Cancer 8: 671-682.

2 Guo J, Longshore S, Nair R, Warner BW (2009) Retinoblastoma protein (pRb), but not $\mathrm{p} 107$ or $\mathrm{p} 130$, is required for maintenance of enterocyte quiescence and differentiation in small intestine. J Biol Chem 284: 134-140.

3 Mayhew CN, Bosco EE, Fox SR, Okaya T, Tarapore P, et al. (2005) Liver-specific pRB loss results in ectopic cell cycle entry and aberrant ploidy. Cancer Res 65: 4568-4577.

4 Sage C, Huang M, Vollrath MA, Brown MC, Hinds PW, et al. (2006) Essential role of retinoblastoma protein in mammalian hair cell development and hearing. Proc Natl Acad Sci U S A 103: 7345-7350.

5 Clark AJ, Doyle KM, Humbert PO (2004) Cell-intrinsic requirement for pRb in erythropoiesis. Blood 104: 1324-1326.

6 Spike BT, Dirlam A, Dibling BC, Marvin J, Williams BO, et al. (2004) The $\mathrm{Rb}$ tumor suppressor is required for stress erythropoiesis. EMBO J 23: 4319-4329.

7 Huh MS, Parker MH, Scimè A, Parks R, Rudnicki MA (2004) Rb is required for progression through myogenic differentiation but not maintenance of terminal differentiation. J Cell Biol 166: 865-876.

8 De Falco G, Comes F, Simone C (2006) pRb: master of differentiation. Coupling irreversible cell cycle withdrawal with induction of musclespecific transcription. Oncogene 25: 5244-5249.

9 Mariappan I, Parnaik VK (2005) Sequestration of pRb by cyclin D3 causes intranuclear reorganization of lamin A/C during muscle cell differentiation. Mol Biol Cell 16: 1948-1960.

10 Haigis K, Sage J, Glickman J, Shafer S, Jacks T (2006) The related retinoblastoma (pRb) and $\mathrm{p} 130$ proteins cooperate to regulate homeostasis in the intestinal epithelium. J Biol Chem 281: 638-647.

11 Yang HS, Hinds PW (2007) pRb-mediated control of epithelial cell proliferation and Indian hedgehog expression in mouse intestinal development. BMC Dev Biol 7: 6.

12 Morgenbesser SD, Williams BO, Jacks T, DePinho RA (1994) p53dependent apoptosis produced by Rb-deficiency in the developing mouse lens. Nature 371: 72-74.

13 Kareta MS, Gorges LL, Hafeez S, Benayoun BA, Marro S, et al. (2015) Inhibition of pluripotency networks by the Rb tumor suppressor restricts reprogramming and tumorigenesis. Cell Stem Cell 16: 39-50.

14 Vilas JM, Ferreirós A, Carneiro C, Morey L, Da Silva-Álvarez S, et al. (2015) Transcriptional regulation of Sox2 by the retinoblastoma family of pocket proteins. Oncotarget 6: 2992-3002.

15 Indovina P, Marcelli E, Casini N, Rizzo V, Giordano A (2013) Emerging roles of RB family: new defense mechanisms against tumor progression. J Cell Physiol 228: 525-535.

16 Manning AL, Dyson NJ (2012) RB: mitotic implications of a tumour suppressor. Nat Rev Cancer 12: 220-226.

17 Takahashi C, Sasaki N, Kitajima S (2012) Twists in views on RB functions in cellular signaling, metabolism and stem cells. Cancer Sci 103: 1182-1188.

18 Nicolay BN, Dyson NJ (2013) The multiple connections between pRB and cell metabolism. Curr Opin Cell Biol 25: 735-740.

19 Viatour P, Sage J (2011) Newly identified aspects of tumor suppression by RB. Dis Model Mech 4: 581-585.
20 Taya Y (1997) RB kinases and RB-binding proteins: new points of view. Trends Biochem Sci 22: 14-17.

21 Weinberg RA (1995) The retinoblastoma protein and cell cycle control. Cell 81: 323-330.

22 Wells J, Boyd KE, Fry CJ, Bartley SM, Farnham PJ (2000) Target gene specificity of $\mathrm{E} 2 \mathrm{~F}$ and pocket protein family members in living cells. Mol Cell Biol 20: 5797-5807.

23 Ishida S, Huang E, Zuzan H, Spang R, Leone G, et al. (2001) Role for E2F in control of both DNA replication and mitotic functions as revealed from DNA microarray analysis. Mol Cell Biol 21: 4684-4699.

24 Knudsen ES, Knudsen KE (2008) Tailoring to RB: tumour suppressor status and therapeutic response. Nat Rev Cancer 8: 714-724.

25 Ren B, Cam H, Takahashi Y, Volkert T, Terragni J, et al. (2002) E2F integrates cell cycle progression with DNA repair, replication, and G(2)/M checkpoints. Genes Dev 16: 245-256.

26 Zhang HS, Gavin M, Dahiya A, Postigo AA, Ma D, et al. (2000) Exit from $\mathrm{G} 1$ and $\mathrm{S}$ phase of the cell cycle is regulated by repressor complexes containing HDAC-Rb-hSWI/SNF and Rb-hSWI/SNF. Cell 101: 79-89.

27 Rubin SM (2013) Deciphering the retinoblastoma protein phosphorylation code. Trends Biochem Sci 38: 12-19.

28 Attwooll C, Lazzerini Denchi E, Helin K (2004) The E2F family: specific functions and overlapping interests. EMBO J 23: 4709-4716.

29 Burke JR, Deshong AJ, Pelton JG, Rubin SM (2010) Phosphorylationinduced conformational changes in the retinoblastoma protein inhibit E2F transactivation domain binding. J Biol Chem 285: 1628616293.

30 Dick FA, Rubin SM (2013) Molecular mechanisms underlying RB protein function. Nat Rev Mol Cell Biol 14: 297-306.

31 Berman SD, Yuan TL, Miller ES, Lee EY, Caron A, et al. (2008) The retinoblastoma protein tumor suppressor is important for appropriate osteoblast differentiation and bone development. Mol Cancer Res 6: 1440-1451.

32 Mendoza-Maldonado R, Paolinelli R, Galbiati L, Giadrossi S, Giacca $M(2010)$ Interaction of the retinoblastoma protein with Orc1 and its recruitment to human origins of DNA replication. PLoS One 5: e13720.

33 Yamasaki L, Bronson R, Williams BO, Dyson NJ, Harlow E, et al. (1998) Loss of E2F-1 reduces tumorigenesis and extends the lifespan of $\mathrm{Rb} 1(+/-)$ mice. Nat Genet 18: 360-364.

34 Parisi T, Yuan TL, Faust AM, Caron AM, Bronson R, et al. (2007) Selective requirements for $\mathrm{E} 2 \mathrm{f} 3$ in the development and tumorigenicity of $\mathrm{Rb}$ deficient chimeric tissues. Mol Cell Biol 27: 2283-2293.

35 Toki H, Inoue M, Minowa O, Motegi H, Saiki Y, et al. (2014) Novel retinoblastoma mutation abrogating the interaction to E2F2/, but not E2F, led to selective suppression of thyroid tumors. Cancer Sci 105: 1360-1368.

36 Vormer TL, Wojciechowicz K, Dekker M, de Vries S, van der Wal A, et al. (2014) RB family tumor suppressor activity may not relate to active silencing of E2F target genes. Cancer Res 74: 5266-5276.

37 Kolupaeva V, Janssens V (2013) PP1 and PP2A phosphatases-cooperating partners in modulating retinoblastoma protein activation. FEBS J 280: 627-643.

38 Tamrakar S, Rubin E, Ludlow JW (2000) Role of pRB dephosphorylation in cell cycle regulation. Front Biosci 5: D121-137. 
39 Durfee T, Becherer K, Chen PL, Yeh SH, Yang Y, et al. (1993) The retinoblastoma protein associates with the protein phosphatase type 1 catalytic subunit. Genes Dev 7: 555-569.

40 Hirschi A, Cecchini M, Steinhardt RC, Schamber MR, Dick FA, et al. (2010) An overlapping kinase and phosphatase docking site regulates activity of the retinoblastoma protein. Nat Struct Mol Biol 17: 10511057.

41 Choy MS, Hieke M, Kumar GS, Lewis GR, Gonzalez-DeWhitt KR, et al. (2014) Understanding the antagonism of retinoblastoma protein dephosphorylation by PNUTS provides insights into the PP1 regulatory code. Proc Natl Acad Sci U S A 111: 4097-4102.

42 Udho E, Tedesco VC, Zygmunt A, Krucher NA (2002) PNUTS (phosphatase nuclear targeting subunit) inhibits retinoblastomadirected PP1 activity. Biochem Biophys Res Commun 297: 463-467.

43 Manning AL, Longworth MS, Dyson NJ (2010) Loss of pRB causes centromere dysfunction and chromosomal instability. Genes Dev 24: 1364-1376.

44 Manning AL, Yazinski SA, Nicolay B, Bryll A, Zou L, et al. (2014) Suppression of genome instability in pRB-deficient cells by enhancement of chromosome cohesion. Mol Cell 53: 993-1004.

45 Hernando E, Nahlé Z, Juan G, Diaz-Rodriguez E, Alaminos M, et al. (2004) Rb inactivation promotes genomic instability by uncoupling cell cycle progression from mitotic control. Nature 430: 797-802.

46 Nath S, Banerjee T, Sen D, Das T, Roychoudhury S (2011) Spindle assembly checkpoint protein Cdc20 transcriptionally activates expression of ubiquitin carrier protein UbcH10. J Biol Chem 286: 15666-15677.

47 Nath S, Chowdhury A, Dey S, Roychoudhury A, Ganguly A, et al. (2015) Deregulation of Rb-E2F1 axis causes chromosomal instability by engaging the transactivation function of Cdc20-anaphasepromoting complex/cyclosome. Mol Cell Biol 35: 356-369.

48 Uchida C, Hattori T, Takahashi H, Yamamoto N, Kitagawa M, et al. (2014) Interaction between RB protein and NuMA is required for proper alignment of spindle microtubules. Genes Cells 19: 89-96.

49 Knudsen ES, Wang JY (2010) Targeting the RB-pathway in cancer therapy. Clin Cancer Res 16: 1094-1099.

50 Amato A, Lentini L, Schillaci T, lovino F, Di Leonardo A (2009) RNAi mediated acute depletion of retinoblastoma protein $(p R b)$ promotes aneuploidy in human primary cells via micronuclei formation. BMC Cell Biol 10: 79.

51 Isaac CE, Francis SM, Martens AL, Julian LM, Seifried LA, et al. (2006) The retinoblastoma protein regulates pericentric heterochromatin. Mol Cell Biol 26: 3659-3671.

52 Srinivasan SV, Mayhew CN, Schwemberger S, Zagorski W, Knudsen ES (2007) RB loss promotes aberrant ploidy by deregulating levels and activity of DNA replication factors. J Biol Chem 282: 23867-23877.

53 Machida K, Liu JC, McNamara G, Levine A, Duan L, et al. (2009) Hepatitis $C$ virus causes uncoupling of mitotic checkpoint and chromosomal polyploidy through the Rb pathway. J Virol 83: 1259012600.

54 Manning AL, Benes C, Dyson NJ (2014) Whole chromosome instability resulting from the synergistic effects of $\mathrm{pRB}$ and $\mathrm{p} 53$ inactivation. Oncogene 33: 2487-2494.

55 Carnevale J, Palander O, Seifried LA, Dick FA (2012) DNA damage signals through differentially modified E2F1 molecules to induce apoptosis. Mol Cell Biol 32: 900-912.
56 Chau BN, Pan CW, Wang JY (2006) Separation of anti-proliferation and anti-apoptotic functions of retinoblastoma protein through targeted mutations of its A/B domain. PLoS One 1: e82.

57 Ianari A, Natale T, Calo E, Ferretti E, Alesse E, et al. (2009) Proapoptotic function of the retinoblastoma tumor suppressor protein. Cancer Cell 15: 184-194.

58 Pediconi N, lanari A, Costanzo A, Belloni L, Gallo R, et al. (2003) Differential regulation of E2F1 apoptotic target genes in response to DNA damage. Nat Cell Biol 5: 552-558.

59 Calbó J, Parreño M, Sotillo E, Yong T, Mazo A, et al. (2002) G1 cyclin/cyclin-dependent kinase-coordinated phosphorylation of endogenous pocket proteins differentially regulates their interactions with E2F4 and E2F1 and gene expression. J Biol Chem 277: 50263 50274.

60 Cecchini MJ, Thwaites MJ, Talluri S, MacDonald JI, Passos DT, et al. (2014) A retinoblastoma allele that is mutated at its common E2F interaction site inhibits cell proliferation in gene-targeted mice. Mol Cell Biol 34: 2029-2045.

61 Nguyen DX, Baglia LA, Huang SM, Baker CM, McCance DJ (2004) Acetylation regulates the differentiation-specific functions of the retinoblastoma protein. EMBO J 23: 1609-1618.

62 Markham D, Munro S, Soloway J, O'Connor DP, La Thangue NB (2006) DNA-damage-responsive acetylation of $\mathrm{pRb}$ regulates binding to E2F-1. EMBO Rep 7: 192-198.

63 Carr SM, Munro S, Kessler B, Oppermann U, La Thangue NB (2011) Interplay between lysine methylation and $\mathrm{Cdk}$ phosphorylation in growth control by the retinoblastoma protein. EMBO J 30: 317-327.

64 Dasgupta B, Milbrandt J (2009) AMP-activated protein kinase phosphorylates retinoblastoma protein to control mammalian brain development. Dev Cell 16: 256-270.

65 Cho HS, Hayami S, Toyokawa G, Maejima K, Yamane Y, et al. (2012) RB1 methylation by SMYD2 enhances cell cycle progression through an increase of RB1 phosphorylation. Neoplasia 14: 476-486.

66 Cicchillitti L, Fasanaro P, Biglioli M, et al. (2003) Oxidative stress induces protein phosphatase 2A-dependent dephosphorylation of the pocket proteins pRb, p107, and p130. J Biol Chem 278: 1950919517.

67 Voorhoeve PM, Hijmans EM, Bernards R (1999) Functional interaction between a novel protein phosphatase $2 \mathrm{~A}$ regulatory subunit, PR59, and the retinoblastoma-related p107 protein. Oncogene 18: 515-524.

68 Voorhoeve PM, Watson RJ, Farlie PG, Bernards R, Lam EW (1999) Rapid dephosphorylation of p107 following UV irradiation. Oncogene 18: 679-688.

69 Kolupaeva V, Laplantine E, Basilico C (2008) PP2A-mediated dephosphorylation of p107 plays a critical role in chondrocyte cell cycle arrest by FGF. PLoS One 3: e3447.

70 Soprano KJ, Purev E, Vuocolo S, Soprano DR (2006) Rb2/p130 and protein phosphatase 2A: key mediators of ovarian carcinoma cell growth suppression by all-trans retinoic acid. Oncogene 25: 53155325.

71 Vuocolo S, Purev E, Zhang D, Bartek J, Hansen K, et al. (2003) Protein phosphatase $2 \mathrm{~A}$ associates with $\mathrm{Rb} 2 / \mathrm{p} 130$ and mediates retinoic acid-induced growth suppression of ovarian carcinoma cells. J Biol Chem 278: 41881-41889.

72 Purev E, Soprano DR, Soprano KJ (2011) PP2A interaction with Rb2/ p130 mediates translocation of $\mathrm{Rb} 2 / \mathrm{p} 130$ into the nucleus in all- 
trans retinoic acid-treated ovarian carcinoma cells. J Cell Physiol 226 1027-1034.

73 Dedinszki D, Kiss A, Márkász L, Márton A, Tóth E, et al. (2015) Inhibition of protein phosphatase- 1 and $-2 A$ decreases the chemosensitivity of leukemic cells to chemotherapeutic drugs. Cell Signal 27: 363-372.

74 Giacinti C, Giordano A (2006) RB and cell cycle progression. Oncogene 25: 5220-5227.

75 Magnaghi-Jaulin L, Groisman R, Naguibneva I, Robin P, Lorain S, et al. (1998) Retinoblastoma protein represses transcription by recruiting a histone deacetylase. Nature 391: 601-605.

76 Ferreira R, Naguibneva I, Pritchard LL, Ait-Si-Ali S, Harel-Bellan A (2001) The Rb/chromatin connection and epigenetic control: opinion. Oncogene 20: 3128-3133.

77 Takahashi Y, Rayman JB, Dynlacht BD (2000) Analysis of promoter binding by the E2F and $\mathrm{PRB}$ families in vivo: distinct $\mathrm{E} 2 \mathrm{~F}$ proteins mediate activation and repression. Genes Dev 14: 804-816.

78 Gonzalo S, García-Cao M, Fraga MF, Schotta G, Peters AH, et al. (2005) Role of the RB1 family in stabilizing histone methylation at constitutive heterochromatin. Nat Cell Biol 7: 420-428.

79 Nielsen SJ, Schneider R, Bauer UM, Bannister AJ, Morrison A, et al. (2001) Rb targets histone $\mathrm{H} 3$ methylation and HP1 to promoters. Nature 412: 561-565.

80 Siddiqui H, Fox SR, Gunawardena RW, Knudsen ES (2007) Loss of RB compromises specific heterochromatin modifications and modulates HP1alpha dynamics. J Cell Physiol 211: 131-137.

81 Pradhan S, Kim GD (2002) The retinoblastoma gene product interacts with maintenance human DNA (cytosine-5) methyltransferase and modulates its activity. EMBO J 21: 779-788.

82 Robertson KD, Ait-Si-Ali S, Yokochi T, Wade PA, Jones PL, et al. (2000) DNMT1 forms a complex with Rb, E2F1 and HDAC1 and represses transcription from E2F-responsive promoters. Nat Genet 25: 338-342.

83 Shamma A, Suzuki M, Hayashi N, Kobayashi M, Sasaki N, et al. (2013) ATM mediates pRB function to control DNMT1 protein stability and DNA methylation. Mol Cell Biol 33: 3113-3124.

84 Lin SP, Chiu FY, Wang Y, Yen ML, Kao SY, et al. (2014) RB maintains quiescence and prevents premature senescence through upregulation of DNMT1 in mesenchymal stromal cells. Stem Cell Reports 3: 975-986

85 Slack A, Pinard M, Araujo FD, Szyf M (2001) A novel regulatory element in the dnmt1 gene that responds to co-activation by $\mathrm{Rb}$ and c-Jun. Gene 268: 87-96.

86 Iurlaro R, León-Annicchiarico CL, Muñoz-Pinedo C (2014) Regulation of cancer metabolism by oncogenes and tumor suppressors. Methods Enzymol 542: 59-80.

87 Annicotte JS, Blanchet E, Chavey C, lankova I, Costes S, et al. (2009) The CDK4-pRB-E2F1 pathway controls insulin secretion. Nat Cell Biol 11: 1017-1023.

88 Shamma A, Takegami Y, Miki T, Kitajima S, Noda M, et al. (2009) Rb Regulates DNA damage response and cellular senescence through E2F-dependent suppression of N-ras isoprenylation. Cancer Cell 15: 255-269.

89 Reynolds MR, Lane AN, Robertson B, Kemp S, Liu Y, et al. (2014) Control of glutamine metabolism by the tumor suppressor $\mathrm{Rb}$. Oncogene 33: 556-566.

90 Blanchet E, Annicotte JS, Lagarrigue S, Aguilar V, Clapé C, et al. (2011)
E2F transcription factor-1 regulates oxidative metabolism. Nat Cell Biol 13: 1146-1152.

91 Sankaran VG, Orkin SH, Walkley CR (2008) Rb intrinsically promotes erythropoiesis by coupling cell cycle exit with mitochondrial biogenesis. Genes Dev 22: 463-475.

92 Hansen JB, Jørgensen C, Petersen RK, Hallenborg P, De Matteis R, et al. (2004) Retinoblastoma protein functions as a molecular switch determining white versus brown adipocyte differentiation. Proc Nat Acad Sci U S A 101: 4112-4117.

93 Wang H, Bauzon F, Ji P, Xu X, Sun D, et al. (2010) Skp2 is required for survival of aberrantly proliferating Rb1-deficient cells and for tumorigenesis in Rb1+/- mice. Nat Genet 42: 83-88.

94 Xu XL, Singh HP, Wang L, Qi DL, Poulos BK, et al. (2014) Rb suppresses human cone-precursor-derived retinoblastoma tumours. Nature 514: 385-388.

95 Sharma A, Yeow WS, Ertel A, Coleman I, Clegg N, et al. (2010) The retinoblastoma tumor suppressor controls androgen signaling and human prostate cancer progression. J Clin Invest 120: 4478-4492.

96 Arima Y, Inoue Y, Shibata T, Hayashi H, Nagano O, et al. (2008) Rb depletion results in deregulation of E-cadherin and induction of cellular phenotypic changes that are characteristic of the epithelialto-mesenchymal transition. Cancer Res 68: 5104-5112.

97 Collins AS, Nakahara T, Do A, Lambert PF (2005) Interactions with pocket proteins contribute to the role of human papillomavirus type 16 E7 in the papillomavirus life cycle. J Virol 79: 14769-14780.

98 McLaughlin-Drubin ME, Huh KW, Münger K (2008) Human papillomavirus type 16 E7 oncoprotein associates with E2F6. J Virol 82: 8695-8705.

99 Chen J (2015) Signaling pathways in HPV-associated cancers and therapeutic implications. Rev Med Virol 25 Suppl 1: 24-53.

100 Aslanian A, laquinta PJ, Verona R, Lees JA (2004) Repression of the Arf tumor suppressor by E2F3 is required for normal cell cycle kinetics. Genes Dev 18: 1413-1422.

101 Chen D, Pacal M, Wenzel P, Knoepfler PS, Leone G, et al. (2009) Division and apoptosis of E2f-deficient retinal progenitors. Nature 462: 925-929.

102 Drosten M, Dhawahir A, Sum EY, Urosevic J, Lechuga CG, et al. (2010) Genetic analysis of Ras signalling pathways in cell proliferation, migration and survival. EMBO J 29: 1091-1104.

103 Drosten M, Sum EY, Lechuga CG, Simón-Carrasco L, Jacob HK, et al. (2014) Loss of p53 induces cell proliferation via Ras-independent activation of the Raf/Mek/Erk signaling pathway. Proc Natl Acad Sci USA 111: 15155-15160.

104 Kitajima S, Kohno S, Kondoh A, Sasaki N, Nishimoto Y, et al. (2015) Undifferentiated state induced by $\mathrm{Rb}-\mathrm{p} 53$ double inactivation in mouse thyroid neuroendocrine cells and embryonic fibroblasts. Stem Cells in press

105 Ferecatu I, Le Floch N, Bergeaud M, Rodríguez-Enfedaque $A$, Rincheval V, et al. (2009) Evidence for a mitochondrial localization of the retinoblastoma protein. BMC Cell Biol 10: 50

106 Hilgendorf KI, Leshchiner ES, Nedelcu S, Maynard MA, Calo E, et al. (2013) The retinoblastoma protein induces apoptosis directly at the mitochondria. Genes Dev 27: 1003-1015.

107 Martinou JC, Youle RJ (2011) Mitochondria in apoptosis: Bcl-2 family members and mitochondrial dynamics. Dev Cell 21: 92-101. 
108 Antonucci LA, Egger JV, Krucher NA (2014) Phosphorylation of the Retinoblastoma protein $(\mathrm{Rb})$ on serine-807 is required for association with Bax. Cell Cycle 13: 3611-3617.

109 De Leon G, Sherry TC, Krucher NA (2008) Reduced expression of PNUTS leads to activation of Rb-phosphatase and caspase-mediated apoptosis. Cancer Biol Ther 7: 833-841.

110 De Leon G, Cavino M, D'Angelo M, Krucher NA (2010) PNUTS knockdown potentiates the apoptotic effect of Roscovitine in breast and colon cancer cells. Int J Oncol 36: 1269-1275.

111 Wang RH, Liu CW, Avramis VI, Berndt N (2001) Protein phosphatase 1alpha-mediated stimulation of apoptosis is associated with dephosphorylation of the retinoblastoma protein. Oncogene 20: 6111-6122.

112 Krucher NA, Rubin E, Tedesco VC, Roberts MH, Sherry TC, et al. (2006) Dephosphorylation of $\mathrm{Rb}$ (Thr-821) in response to cell stress. Exp Cell Res 312: 2757-2763.

113 Lentine B, Antonucci L, Hunce R, Edwards J, Marallano V, et al. (2012) Dephosphorylation of threonine-821 of the retinoblastoma tumor suppressor protein $(\mathrm{Rb})$ is required for apoptosis induced by UV and Cdk inhibition. Cell Cycle 11: 3324-3330.

114. Mihara M, Erster S, Zaika A, Petrenko O, Chittenden T, et al. (2003) p53 has a direct apoptogenic role at the mitochondria. Mol Cell 11: 577-590.

115 Attardi LD, Sage J (2013) RB goes mitochondrial. Genes Dev 27: $975-$ 979.

116 Sherr CJ, McCormick F (2002) The RB and p53 pathways in cancer. Cancer Cell 2: 103-112.

117 Lipinski MM, Macleod KF, Williams BO, Mullaney TL, Crowley D, et al. (2001) Cell-autonomous and non-cell-autonomous functions of the $\mathrm{Rb}$ tumor suppressor in developing central nervous system. EMBO J 20: 3402-3413.

118 Wu L, de Bruin A, Saavedra HI, Starovic M, Trimboli A, et al. (2003) Extra-embryonic function of $\mathrm{Rb}$ is essential for embryonic development and viability. Nature 421: 942-947.

119 de Bruin A, Wu L, Saavedra HI, Wilson P, Yang Y, et al. (2003) Rb function in extraembryonic lineages suppresses apoptosis in the CNS of Rb-deficient mice. Proc Natl Acad Sci U S A 100: 6546-6551.

120 Pacek M, Walter JC (2004) A requirement for MCM7 and Cdc45 in chromosome unwinding during eukaryotic DNA replication. EMBO J 23: 3667-3676

121 Sterner JM, Dew-Knight S, Musahl C, Kornbluth S, Horowitz JM (1998) Negative regulation of DNA replication by the retinoblastoma protein is mediated by its association with MCM7. Mol Cell Biol 18: 2748-2757.

122 Mukherjee P, Winter SL, Alexandrow MG (2010) Cell cycle arrest by transforming growth factor beta 1 near $\mathrm{G} 1 / \mathrm{S}$ is mediated by acute abrogation of prereplication complex activation involving an $\mathrm{Rb}$ MCM interaction. Mol Cell Biol 30: 845-856.

123 lavarone A, Massagué J (1999) E2F and histone deacetylase mediate transforming growth factor beta repression of cdc25A during keratinocyte cell cycle arrest. Mol Cell Biol 19: 916-922.
124 Frederick JP, Liberati NT, Waddell DS, Shi Y, Wang XF (2004) Transforming growth factor beta-mediated transcriptional repression of c-myc is dependent on direct binding of Smad3 to a novel repressive Smad binding element. Mol Cell Biol 24: 25462559.

125 Toyokawa G, Masuda K, Daigo Y, Cho HS, Yoshimatsu M, et al. (2011) Minichromosome Maintenance Protein 7 is a potential therapeutic target in human cancer and a novel prognostic marker of non-small cell lung cancer. Mol Cancer 10: 65

126 Korah J, Falah N, Lacerte A, Lebrun JJ (2012) A transcriptionally active pRb-E2F1-P/CAF signaling pathway is central to TGF $\hat{I}^{2}$-mediated apoptosis. Cell Death Dis 3: e407.

127 Adams PD (2009) Healing and hurting: molecular mechanisms, functions, and pathologies of cellular senescence. Mol Cell 36: 2-14.

128 Narita M, NÅ@nez S, Heard E, Narita M, Lin AW, et al. (2003) Rbmediated heterochromatin formation and silencing of E2F target genes during cellular senescence. Cell 113: 703-716.

129 Zhang R, Adams PD (2007) Heterochromatin and its relationship to cell senescence and cancer therapy. Cell Cycle 6: 784-789.

130 Zhang R, Chen W, Adams PD (2007) Molecular dissection of formation of senescence-associated heterochromatin foci. Mol Cell Biol 27: 2343-2358.

131 Zhang R, Poustovoitov MV, Ye X, Santos HA, Chen W, et al. (2005) Formation of MacroH2A-containing senescence-associated heterochromatin foci and senescence driven by ASF1a and HIRA. Dev Cell 8: 19-30.

132 Kosar M, Bartkova J, Hubackova S, Hodny Z, Lukas J, et al. (2011) Senescence-associated heterochromatin foci are dispensable for cellular senescence, occur in a cell type- and insult-dependent manner and follow expression of p16(ink4a). Cell Cycle 10: 457-468.

133 Zhang Y, Gao Y, Zhao L, Han L, Lu Y, et al. (2013) Mitogen-activated protein kinase $\mathrm{p} 38$ and retinoblastoma protein signaling is required for DNA damage-mediated formation of senescence-assoiciated heterochromatic foci in tumour cells. FEBS J 280: 4625-4639.

134 Chicas A, Kapoor A, Wang X, Aksoy O, Evertts AG, et al. (2012) H3K4 demethylation by Jarid $1 a$ and Jarid $1 b$ contributes to retinoblastomamediated gene silencing during cellular senescence. Proc Natl Acad Sci U S A 109: 8971-8976.

135 Campisi J (2005) Senescent cells, tumor suppression, and organismal aging: good citizens, bad neighbors. Cell 120: 513-522.

136 Ferbeyre G, de Stanchina E, Querido E, Baptiste N, Prives C, et al. (2000) PML is induced by oncogenic ras and promotes premature senescence. Genes Dev 14: 2015-2027.

137 Vernier M, Bourdeau V, Gaumont-Leclerc MF, Moiseeva O, Bégin $V$, et al. (2011) Regulation of E2Fs and senescence by PML nuclear bodies. Genes Dev 25: 41-50.

138 Aksoy O, Chicas A, Zeng T, Zhao Z, McCurrach M, et al. (2012) The atypical E2F family member E2F7 couples the $\mathrm{p} 53$ and RB pathways during cellular senescence. Genes Dev 26: 1546-1557.

139 Chicas A, Wang X, Zhang C, McCurrach M, Zhao Z, et al. (2010) Dissecting the unique role of the retinoblastoma tumor suppressor during cellular senescence. Cancer Cell 17: 376-387. 